\title{
Preventative treatment for infantile epilepsy
}

\begin{tabular}{|c|c|}
\hline $\begin{array}{l} \\
\text { This short-term } \\
\text { treatment also } \\
\text { prevented the } \\
\text { structural and } \\
\text { behavioural } \\
\text { pathologies }\end{array}$ & $\begin{array}{l}\text { Epilepsy is characterized by } \\
\text { abnormal, hyperexcitable neural } \\
\text { connections, many of which form } \\
\text { during early post-natal life. Work } \\
\text { published in Nature Medicine has } \\
\text { now shown that the abnormalities in } \\
\text { some genetic forms of epilepsy can } \\
\text { be corrected in mice by short-term } \\
\text { post-natal treatment with a small } \\
\text { molecule that alters the neuronal } \\
\text { chloride balance. } \\
\text { Neural excitability is regulated } \\
\text { in part by voltage-gated potassium } \\
\text { channels known as M channels. } \\
\text { These channels are formed by the } \\
\text { heterodimerization of potassium } \\
\text { voltage-gated channel } 7 \text { (Kv7) family }\end{array}$ \\
\hline
\end{tabular}

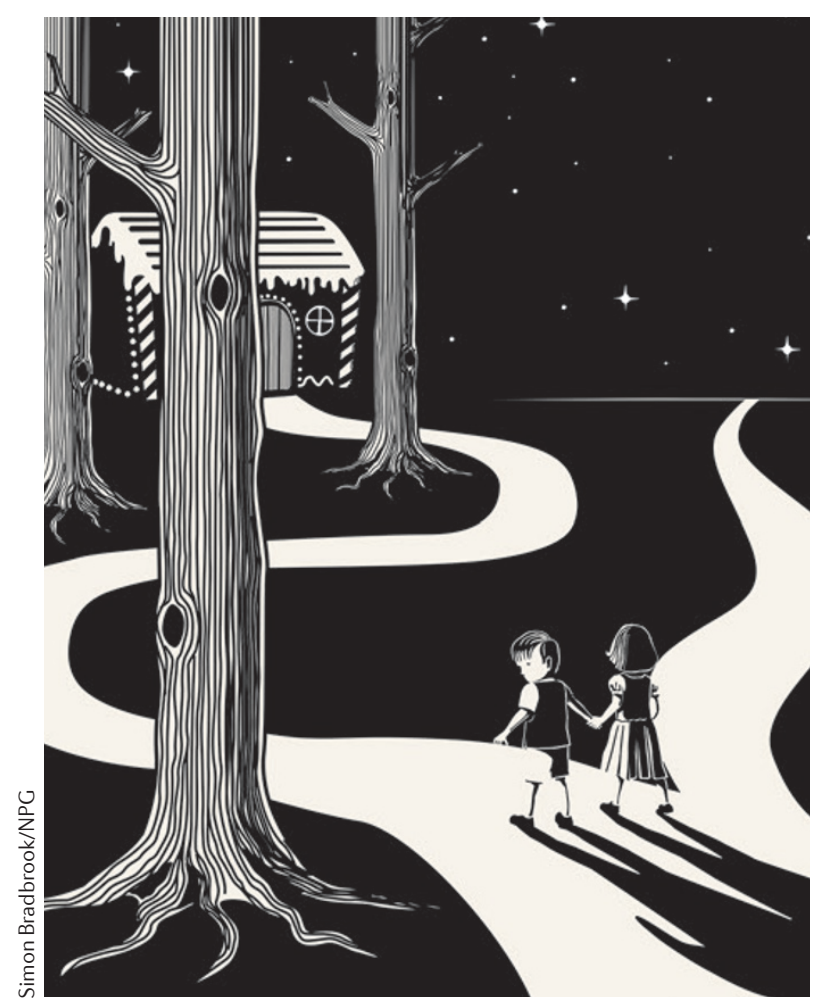

members, including KCNQ2 and KCNQ3, mutations in which are associated with dominant inherited forms of benign idiopathic epilepsy and severe neonatal epileptic encephalopathy.

In previous work, overexpression of dominant-negative KCNQ2

(Kv7DN) in mice ablated neuronal Kv7-mediated M channel currents, and expression of this protein during only the first 2 post-natal weeks was sufficient to induce epilepsy in adults. Conversely, suppressing expression of this transgene during the first 2 post-natal weeks could prevent the morphological and behavioural changes associated with Kv7DN expression, even though these mice had abnormal $\mathrm{M}$ currents from post-natal week 3 .

In their recent paper, the authors further characterize the abnormal circuitry in these mice. Most notably, hippocampal and cortical network activities were altered in post-natal day 10 (P10)-P11 and P6-P7, respectively, and the Kv7DN-expressing neurons fired more action potentials in bursts with a shorter interburst interval than control neurons did.

Barbiturates and other $\gamma$-aminobutyric acid (GABA) mimetics are currently used to treat infantile epilepsy, but their efficacy is limited and their safety is questionable. The authors reasoned that altering network activity during early post-natal life could normalize the maturation of GABAergic signalling and optimise the balance between excitation and inhibition, which could prevent the development of epilepsy. During early neuronal development,
GABA can be an excitatory neurotransmitter because of the expression of the $\mathrm{Na}-\mathrm{K}-\mathrm{Cl}$ symporter (NKCC1) and low expression of KCC2, which occurs only during development and maintains such high intracellular chloride concentrations that the chloride concentration gradient across the membrane of immature neurons is in the opposite direction of that found in adult neurons.

The authors therefore treated P1-P14 Kv7DN mice with bumetanide, which blocks NKCC1 and is therefore used as a diuretic to treat heart failure. Bumetanide should reduce intracellular chloride concentrations and thereby attenuate GABA-mediated depolarization in immature neurons and increase GABA-mediated hyperpolarization in any mature neurons that still express NKCC1. Indeed, bumetanide treatment during P1-P14 normalized the network activity in Kv7DN mice by P7-P14. This short-term treatment also prevented the structural and behavioural pathologies that develop in Kv7DN mice by 6-8 weeks of age, suggesting that a transient treatment can establish normal hippocampal excitability, which then sets the stage for future neuronal activity. This treatment had no effect on wild-type mice, suggesting that it is safe.

These data suggest that targeting critical windows, such as the establishment of neural circuits, could prevent the development of epilepsy or other diseases.

Megan Cully

ORIGINAL ARTICLE Marguet, S. L. Treatment during a vulnerable developmental period rescues a genetic epilepsy. Nat. Med. 21, 1436-1444 (2015) 